\title{
El mundo del trabajo y de los obreros en el pensamiento y la obra del beato Marcelo Spínola y Maestre ${ }^{1}$
}

\author{
The world of work and workers from the point \\ of view of beatus Marcelo Spinola y Maestre
}

\author{
José-Leonardo Ruiz Sánchez \\ Universidad de Sevilla \\ orcid.org/0000-0002-3392-4475
}

Resumen: El Beato Marcelo Spínola y Maestre (1835-1906) mantuvo desde primera hora una honda preocupación por los problemas sociales distinguiendo nítidamente entre caridad y justicia social, sintonizando así con los planteamientos sociales de León XIII expresados en la Rerum Novarum (1891). En sus distintos escritos que redactó en su condición de obispo (de Coria-Cáceres, Málaga y Sevilla entre 1881 y 1906) dejó plasmado su pensamiento sobre la necesidad de estudiar la problemática social. Cuestionando que las relaciones entre los trabajadores y los poseedores de capital se regulasen únicamente por la ley de la oferta y la demanda (que defendía el individualismo liberal del momento) denunció la acumulación de las riquezas más allá de lo que era justo en manos de algunos, sin darle además ninguna utilidad tendente a lograr un equitativo reparto de la riqueza pues, de ello, resultaba un obrero oprimido socialmente que no le quedaba otra opción sino la de revelarse contra los que detentaban el poder económico y político (como promovía el socialismo); entre ambos mo- delos debía abrirse camino la propuesta de la Iglesia. Fiel a este planteamiento, junto a la implantación en sus diócesis de los instrumentos planteados por el conde Mun y del P.Vicent, que eran los que estaban de moda, puso también en marcha otras iniciativas para preveer el mal y evitar sus consecuencias.

Palabras clave: Beato Marcelo Spínola y Maestre (1835-1906), Diócesis de Málaga, Archidiócesis de Sevilla, Doctrina Social de la Iglesia, justicia social, León XIII.

Abstract: Beatus Marcelo Spínola y Maestre (1835-1906) was from the very beginning deeply concerned about social problems, making a clear distinction between charity and social justice, in line with the social proposals of Leo XIII as expressed in Rerum Novarum (1891). In his various writings as bishop (of Coria-Cáceres, Malaga and Seville between 1881 and 1906) he expressed his thoughts on the need to study social problems. Questioning the fact that relations between workers and the owners of capital were regulated solely by 
the law of supply and demand (which the liberal individualism of the time defended), he denounced the accumulation of wealth beyond what was fair in the hands of a few. Moreover, he did not give it any usefulness in achieving an equitable distribution of wealth, since this resulted in a socially oppressed worker who had no other option but to rebel against those who held economic and political power (as promoted by socialism). Between the two models, the Church's proposal had to find its way.
Faithful to this approach, along with the implementation in his dioceses of the instruments put forward by Count Mun and Fr. Vicent, which were the ones in vogue, he also set in motion other initiatives to foresee evil and prevent its consequences.

Keywords: Beatus Marcelo Spínola y Maestre (1835-1906), Diocese of Málaga, Archdiocese of Seville, Social Doctrine of the Church, social justice, Leo XIII.

\begin{abstract}
"No nos oponemos a que se estudien los problemas sociales, ni a que se inquiera a la luz de la ciencia el modo de mejorar la condición de los que sufren buscándose medios para impedir, sin atentar a la justicia, la acumulación de la propiedad en solo unas cuantas manos, para procurar la buena y equitativa distribución de las riquezas, para evitar que los poseedores del capital vejen u opriman al infeliz obrero, y para conciliar el respeto a la autoridad con la libertad del ciudadano. ¿Cómo habíamos de oponernos a esto? Sería no tener amor a los débiles y a los flacos, lo que no se concibe en un cristiano, en un Sacerdote, en un Obispo, o carecer totalmente de fe en lo que puede y vale el esfuerzo humano". ${ }^{2}$
\end{abstract}

Las anteriores letras, escritas por el beato Marcelo Spínola y Maestre en 1892, cuando era obispo de Málaga, nos muestran la preocupación que sobre los problemas sociales tenía a finales del siglo XIX uno de los, sin duda, más preclaros miembros del episcopado español del momento. Sobre la sólida base del mensaje evangélico que conlleva la opción de los cristianos -con independencia de su rango- por los más pobres, añade el beato Spínola una clara denuncia contra la acumulación de riquezas en manos de unos pocos, más

1 El presente trabajo fue elaborado en 2018 para la Fundación Cardenal Spínola de Lucha contra el Paro (Marcelo Spinola y Maestre: la santidad en la cuestión social.- Documento 2018). Previa autorización de los responsables de la Fundación se publica aquí para que alcance una mayor difusión el texto además de estar claramente en sintonía con la temática en este Anuario.

2 Marcelo SPÍNOLAY MAESTRE [MSyM en adelante], A nuestros amados diocesanos, Málaga, 18 de febrero de 1892. En Boletín Oficial del Obispado de Málaga [en adelante BOOM], 1892, p. 46. 
allá de lo que sería justo, a fin de favorecer una "buena y equitativa" distribución de la riqueza. Su opción, según se desprende del texto, es evitar"sin atentar a la justicia" -en clara referencia a los derechos que debían asistir a una y otra parte- que los poseedores de capital "vejen u opriman al infeliz obrero", para que así se concilie el respeto a la autoridad (por parte de quienes se revelaban contra ella, al no tener nada material que perder porque nada poseían) con la libertad individual común a todo ciudadano por la que nada podía obstaculizar el afán por enriquecerse, libertad de la que carecerían sin duda quienes estaban esclavizados por su propia miseria. Más allá del rigor con el que se formuló el argumento, sin apasionamientos, los calificativos empleados por el autor del texto mostraban meridianamente cómo su pensamiento y su corazón se hallaban en clara sintonía con el mensaje de Cristo.

\section{UNA CUESTIÓN, LA SOCIAL, NECESITADA DE ESTUDIO}

No era la primera vez que reclamaba el estudio de todo lo relacionado con la "cuestión social", término empleado en aquellos momentos; ya lo había hecho con anterioridad como puede cotejarse en el boletín diocesano de Málaga. Un año antes del texto anterior, con ocasión de la promulgación en 1891 de la Rerum novarum, la introdujo a los malacitanos precedida de una extensa circular de su puño y letra. "Bien merece calificarse 'de notable, notabilísimo acontecimiento' la publicación de la Encíclica -decía- en la que Su Santidad el Papa León XIII aborda con entera franqueza el gran problema de los últimos tiempos, por su importancia absoluta y por su relativa trascendencia apellidado 'la cuestión social'". Siendo un problema que "preocupa a todos los ánimos", en el cual el obrero "no sueña sino con reivindicaciones, que estima justas, utilizando para lograrlas cuantos medios a su alcance halla", también era "motivo de constante alarma para los poseedores del 'Capital'" que temían serios conflictos "si la turbada alianza entre ellos y los representantes del trabajo no se restablece pronto", añadía el Beato Spínola. A su estudio - proseguía- se dedicaban los economistas, hombres de Estado, círculos científicos y otros foros y, por su parte, pedía también a los sacerdotes"que lean, estudien y saboreen la Encíclica" además de encargarles que divulgasen y explicasen el texto a sus feligreses, aunque 
"no todos entenderán los grandes pensamientos, encerrados en este documento verdaderamente inmortal, si no se les presentan desnudos del hermoso ropaje, con que los atavía la pluma del Papa, y si no se les traduce al lenguaje más vulgar". ${ }^{3}$

Sin adentramos con detenimiento en los planteamientos ideológicos imperantes en el momento en el que se redactaron los anteriores textos no podremos calibrar la importancia y el valor que encierran las letras del beato Spínola; desde la perspectiva actual puede que ni siquiera nos llamase la atención, por parecernos algo normal y en absoluto excepcional. Hoy en la mayoría de los ordenamientos constitucionales vigentes figura una definición del Estado como democrático "y social", porque es esta una función no menor que se garantiza a través de sus leyes. Los que lean estas líneas seguro que conocen la Doctrina Social de la Iglesia (DSI), donde quedan recogidos entre otros principios los que son aplicables a las relaciones entre el capital y el trabajo -como se decía antaño- entre los patronos y los obreros, en definitiva; pocos sabrán que esa denominación quedó fijada por primera vez en 1931 -por tanto, años después a los que nos ocupan- en la Encíclica Quadragesimo anno.

Estamos en unos momentos anteriores en los que, precisamente, la Iglesia estaba poniendo los cimientos de las DSI. Entonces, cuando León XIII y el beato Marcelo Spínola redactaban los anteriores documentos citados, el modelo por el que se regulaban las relaciones entre el mundo del capital y el trabajo, entre los poseedores de capital y los trabajadores, establecía que era la misma ley por la que se regulaba el mercado, la oferta y la demanda, la que debía aplicarse a esas relaciones. Todo quedaba sometido al imperio de esa única ley que podía favorecer el enriquecimiento abusivo de quienes tenían el capital al tiempo que dejaba completamente desprotegidos a los trabajadores por cuanto, bajo este modelo ideológico individualista, liberalismo económico o capitalismo, no se concebía como necesaria una legislación social que protegiese a la parte más débil en estas relaciones, la del trabajador, ni a los desheredados, situados en la marginalidad e indigencia, que sólo podían esperar algo de las instituciones benéficas y caritativas, la mayoría patrocinadas e impulsadas por la Iglesia.

3 MSyM, Circular no 509, Málaga, 23 de junio de 1891. BOOM, 1891, p.138. 
Esta situación era la establecida a finales del siglo XIX para regular las relaciones económicas en nuestro entorno europeo. Cierto es que para corregirla irrumpía con virulencia, captando adeptos entre los obreros, otros modelos ideológicos que, cuestionando el orden anterior basado en las leyes del mercado, proponían que fuese sólo el Estado, el poder público, quien únicamente regulase estas relaciones. A esto respondían el movimiento internacionalista y las distintas organizaciones políticas y sindicales del proletariado, en estos momentos fundamentalmente el anarquismo y el socialismo, que hacían de la lucha de clases su principal instrumento para la consecución de sus principios y la dirección del Estado. Unos planteamientos que, en palabras del propio beato Spínola, rendían culto"a la teoría hegeliana de la omnipotencia del Estado, [que] hace de este el árbitro de todas las relaciones, y el sólo juez llamado a dirimir con sus sentencias la presente formidable querella". ${ }^{4}$

\section{UNA RESPUESTA DOCTRINAL DISTINTA A LAS IDEOLÓGICAS EXISTENTES}

Es en este complejo contexto es en el que ha de situarse la respuesta doctrinal que dieron a la cuestión las personalidades más relevantes de la Iglesia, comenzando por el Santo Padre. Una situación que, en letras del Beato Marcelo Spínola, daba lugar a un "desquiciamiento general" en el que se veía "cómo andaban revueltas las ideas, y cómo surgen de lados diferentes aspiraciones gigantescas e insensatas, cuyos resultados no pueden vislumbrarse", preguntándose "estremecidos" los pensadores más capacitados si no era que "se acercan los últimos tiempos, y nos encontramos en vísperas de la catástrofe final, anunciada tantas veces y con tan pavorosas frases en los libros sagrados" ${ }^{5}$

Una respuesta valiente ante posicionamientos radicalmente contrapuestos, sostenidos por los dos planteamientos ideológicos más influyentes del momento, que todavía perduran. Sin duda una situación difícil que alarmaba a muchos y preocupaba a todos, en la que "no es posible terciar en la pelea -decía Spínola- sin grave

\footnotetext{
Id. p. 136.

MSyM, A nuestros amados diocesanos, Málaga, 20 de mayo de 1892. En BOOM, 1982, p. 98.
} 
compromiso"y de ahí que, en referencia a León XIII, alabara su actitud y las razones de su compromiso al no permanecer sólo expectante, al margen, dedicando a ello algunas de las encíclicas más sobresalientes de su pontificado ${ }^{6}$. Una valoración sobre el Santo Padre que también podemos aplicar a él, por la actitud y el compromiso que adquirió: su interés por estudiar la cuestión social, como hemos referido más arriba reproduciendo las letras de sus propios documentos, en clara sintonía con los de la Iglesia Universal.

Quedaba claro que entre estos dos modelos ideológicos se establecía una lucha desde intereses muy opuestos, difíciles de avenir, que eran cuestionados desde posiciones eclesiales cuyo fundamento era doctrinal, pues ni se aliaban con las escuelas individualistas, que santificaban la ley del mercado, ni rendían culto a la omnipotencia del Estado. El beato Spínola -en sintonía con Roma- marcaba una oportuna distancia frente a ambos modelos en disputa por la cuestión social por cuanto ninguno de los dos sectores que los auspiciaban respondían a planteamientos cristianos:

"Una cosa llama desde luego la atención, y es que ni los que turban la paz pública declarando guerra a la propiedad, al capital y a los poderes legítimos, ni los que son objeto de sus querellas, el rico que del pobre se olvida, el capitalista que no tiene miramientos con el operario de su taller o de su fábrica, el gobernante, que hiere, lastima, molesta y esquilma a los gobernados, son fieles observadores de la Cuaresma. Seguid sus pasos, y veréis cómo ni ayunan, ni asisten a la Iglesia, a no ser que a ella los lleve el deseo de oír a célebre orador o de escuchar melodías no vulgares, ni oran, ni reciben los Sacramentos. Este hecho por si solo habla muy alto".?

La solución para este enfrentamiento pasaba por buscar, según el Beato Marcelo Spínola, no una respuesta desde las ideologías, sino por trazar conductas morales; en otro momento indicará que en la restauración el orden cristiano en los Estados podría encontrarse no

6 "[..] muestra raro valor y confianza inquebrantable en sus armas quien no se mantiene en actitud expectante, dejando a los hechos el encargo de dar la deseada solución, sino se lanza denodado al campo de las disputas, y pronuncia su fallo, diciendo a los contendientes: No tenéis otro camino para alcanzar paz, que el que yo os propongo y señalo". MSyM, Circular n 509, Málaga, 23 de junio de 1891. En BOOM, 1891, p. 136.

7 MSyM, A nuestros amados diocesanos, Málaga, 18 de febrero de 1892. En BOOM, 1892, pp. 46-7. 
pocos medios para remediar los males que aquejaban a las cuestiones sociales. Desde luego que, a la hora de señalar a los responsables de la situación, tendía a distribuir culpas; pero sin duda tenía un miramiento especial hacia los más perjudicados en este conflicto, los obreros, por cuanto entendía que el enfrentamiento se hacía desde la desigualdad entre los dos contendientes. "Los males nuestros, que son harto graves, -decía- no nacen sólo de las concupiscencias desencadenadas del obrero, sino a ellos en gran manera contribuyen los abusos de los que del obrero se sirven, y los explotan sin miramiento alguno". Y añadía de inmediato los dos abusos más extendidos:

"Es un hecho, sin embargo, innegable que no siempre se ve bien tratado el obrero por los que dueños de capital, lo utilizan para la producción y aumento de la riqueza; consistiendo el abuso en dos puntos principalmente: $1^{\circ}$, en la entidad del salario, que suele no guardar proporción con las necesidades del obrero, siendo causa de que este viva mal, y de que cuando le sobrevienen desgraciados accidentes, hartos comunes en la vida, que le impiden el trabajo, quede sumido en los horrores de la miseria; y $2^{\circ}$ en el exceso del esfuerzo que se le exige, el cual lo enerva, lo debilita y lo envejece o pone inútil antes de sazón, privándole a él mismo de ese tan precioso bien de la salud y la robustez física, que no estimamos en lo que vale, sino cuando lo perdemos, a la familia de su sostén y apoyo, y a la sociedad de un miembro importante". ${ }^{8}$

Y las razones de este proceder se derivaban de la codicia, del egoísmo, del individualismo y, en definitiva, materialismo imperante:

"Depende este mal proceder del capitalista para con el obrero de la sed de lucro, que devora a los hombres de nuestro siglo, sed nacida del deseo de goces, que a todos atormenta, y que ha hecho crecer por manera espantosa las necesidades humanas en los pueblos que se llaman cultos, siendo necesarios caudales inmensos para satisfacerlas.

Si queremos a estas causas diversas de daños tan graves darle un nombre técnico, diremos que las injusticias cometidas con el obrero son obra de la insaciable codicia del capitalista; la cual a su vez procede del sensualismo, como éste se origina en el egoísmo brutal del que posee; de suerte que tenemos aquí toda una generación de monstruos, de fieras más o menos

8 MSyM, A nuestros amados diocesanos, Málaga, 20 de mayo de 1892. En BOOM, 1892, p. 107. 
horrendas, pero todas capaces de causar en la hora menos pensada desastres sin cuento.

El egoísmo es el padre común, el tronco de este horrible árbol genealógico; egoísmo que todo lo sacrifica al Yo, única deidad, que sus sectarios adoran. Hijo de este es el sensualismo, que coloca la dicha en los placeres de los sentidos, y que tras ellos corre desalado, atravesando ríos, trepando montes, cortando, a modo de ejército conquistador, y talando lo que halla a su paso, incendiando y destruyendo cuanto obstáculo se opone a su marcha". ${ }^{9}$

El fin de la radicalidad debía de venir no de la lucha de clases ni de ese enfrentamiento desigual, sino de la colaboración entre ambos. "El rico y el pobre, el capitalista y el obrero, el gobernante y el súbdito caen al fin en la cuenta de que son hermanos, y amaestrados en la escuela de Cristo, deponen sus rencores, iniciándose ese pacto, esa alianza venturosa de la caridad, que corrige las desigualdades de la naturaleza y hasta enmienda los defectos de las leyes"; era su pensamiento y deseo para la Cuaresma de 1892, la primera tras la promulgación de la Rerum novarum:

"Juntando, en fin, a los disidentes en la casa de su común Padre, la Cuaresma los reconcilia, a modo de Mediadora celeste, y en vez de reñir sobre derechos, establece entre los que antes disputaban, noble contienda de abnegación y sacrificios.

No lo dudamos: si la Cuaresma fielmente se observara, todo cambiaría de faz.

Las reformas, las justas reformas deseadas y pedidas en vano, se harían en las costumbres, pasando luego de las costumbres a los códigos, y el orden social inaugurado en la Cuaresma, se perpetuaría, protegido y amparado por la acción siempre benéfica de la Iglesia, y por la fuerza y sanción del Estado". ${ }^{10}$

Frente a la lucha de clases entre quienes poseían la riqueza, los capitalistas, y quienes sólo eran dueños de su esfuerzo manual, los obreros o proletariado, la Iglesia trazaba un camino de reconciliación entre las partes enfrentadas buscando la armonía entre las clases sociales mediante el diálogo, favoreciendo su reunión y convivencia en determinados organismos. Esta fue una de las principales aportaciones que en estos momentos ofrecerá la Iglesia, que

Id., pp. 107-108.

10 MSyM, A nuestros amados diocesanos, Málaga, 18 de febrero de 1892. En BOOM, 1892, pp. 46-7. 
avanzaba sin duda en una respuesta no desde la caridad sino desde la justicia social.

\section{LAS INICIATIVAS PUESTAS EN MARCHA}

El divorcio y antagonismo entre las clases sociales, la lucha entre el proletariado desposeído y la clase patronal dueña de los medios de producción, en definitiva la guerra entre capital y trabajo, buscó como remedio entonces los "círculos católicos de obreros". La obra había sido fundada en Francia por el conde Mun con un exitoso primer período, en los años setenta, por tanto con anterioridad a la Rerum novarum. El círculo era el lugar donde patronos y obreros, distanciados por la economía liberal, entrarían en contacto. Así, las clases superiores conocerían de una manera directa las necesidades de las humildes, lo que facilitaría el cumplimiento de sus deberes de justicia y caridad; y de otra parte, los obreros adquirirían una formación que les llevaría a poder desarrollar mejor sus labores profesionales y una educación que les inclinaría al respeto de la jerarquía social basada en la naturaleza del hombre. En su seno se fueron desarrollando distintos organismos (escuelas de adultos, cooperativas, economatos, bolsas de trabajo, cajas de ahorros, entre otros) que podrían servir de instrumento para lograr con justicia la armonía entre las clases enfrentadas. El papel decisivo asignado a las clases económicas superiores en las primeras organizaciones obreras de esta naturaleza (más tarde -en etapa posterior a la muerte del beato Spínola- evolucionarían) tendieron a impregnar de precariedad a estos círculos, donde subyacía siempre un carácter paternalista ${ }^{11}$. El modelo francés arraigó desde temprana fecha en España siendo el principal propagandista de los mismos el jesuita castellonense P. Antonio Vicent quien, durante su estancia obligatoria en Francia a causa de la expulsión de la Compañía tras la revolución de 1868, los conoció en sus momentos iniciales de manera directa; más tarde también pudo constatar su desarrollo en Alemania y Bélgica. Las nuevas circunstancias políticas abiertas con la llegada al trono de Alfonso XII posibilitaron

11 Aunque antiguo, sigue siendo válido el estudio que hizo en su día José ANDRÉSGALLEGO, Pensamiento y acción social de la Iglesia en España, Madrid, EspasaCalpe, 1984. 
su regreso a España iniciando una intensa propaganda social que, hasta su muerte acaecida en 1912, conllevó el establecimiento por todo el país de centenares de círculos siendo, sin lugar a duda, los instalados en la región levantina -donde su labor fue más destacada- los más pujantes. ${ }^{12}$

Nos consta que el beato Marcelo Spínola y Maestre era un entusiasta de estas obras del P.Vicent. En 1887 consiguió abrir uno de estos círculos en Málaga. En la misma sede, unos años más tarde, cuando planteaba la necesidad de restaurar el orden cristiano, proponía como un recurso que podría dar mucho fruto "la multiplicación de los Círculos de Obreros, que tan maravillosamente sirven, cuando están bien organizados, para alejar a los jóvenes trabajadores de los centros de perdición, en que corrompen sus almas, y hacerles sentir el atractivo de lo espiritual y divino" y, junto a ellos, la propagación de libros, folletos, hojas y diarios de sana lectura, así como los

12 Sobre el proceso de instalación de estas y otras obras de catolicismo social en España existe abundante bibliografía (entre ellas las de Domingo Benavides y José Manuel Cuenca Toribio, con una visión de conjunto) sobre todo referida a sus principales impulsores (P.Vicent, Arboleya Martínez, Gafo y otros), que está recogida en los principales repertorios y en las obras de Historia de la Iglesia en la contemporaneidad. Sobre la situación general de la Archidiócesis de Sevilla, un planteamiento general de todo el período ya figuró en la que fue nuestra tesis doctoral J.L. RUIZ SÁNCHEZ, Política e Iglesia durante la Restauración. La Liga Católica de Sevilla (1901-1923), Sevilla, Diputación, 1994;“'La acción social católica en la provincia de Huelva (1903-1922). Algunas consideraciones para su estudio y comprensión", en Hueva en su historia, Huelva, Universidad, 1994, pp. 457-484; "Iglesia y secularización en la Época Contemporánea. El movimiento católico en Estepa, en V Jornadas sobre Historia de Estepa. La época contemporánea, Estepa, Ayuntamiento, 2003, pp. 119-162;"Catolicismo social en la Vega del Guadalquivir de Sevilla (1900-1925)", en II Jornadas de Historia sobre la Vega del Guadalquivir. Edad Contemporánea, Sevilla, APSCIL, 2007, pp. 123-154; “El movimiento católico en el Arciprestazgo de Carmona. Prensa católica y catolicismo social (1896136)", en De la Restauración Borbónica a la Guerra Civil, 1874-1936. Actas del VI Congreso de Historia de Carmona, Carmona, Universidad de Sevilla, 2009, pp. 239268. J. SÁNCHEZ JIMÉNEZ, "Sindicalismo católico agrario en Andalucía. Los Sindicatos Católicos libres del P. Gerard, O.P. e Jerez de la Frontera", en Actas del I Congreso de Historia de Andalucía. Andalucía Contemporánea, Córdoba, Monte de Piedad y Caja de Ahorros, 1979, t. II, pp.437-465. Con respecto a los problemas de las fuentes en este mismo ámbito geográfico vid."Fuentes eclesiales para el estudio del catolicismo social en la baja Andalucía" que presentamos al XXX Congreso de la Asociación de Archiveros de la Iglesia en España, celebrado en Jaén y Guadix en 2017 (en prensa). 
catecismos, especialmente aquellos que los franceses denominaban de perseverancia. ${ }^{13}$

Otro tanto venía a decir recién instalado en la sede de Sevilla. Poco antes había tenido lugar la reunión de las corporaciones católicas-obreras de España inspirada por el P.Vicent. El hecho dio lugar a una extensa circular en la que denunciaba por un lado cómo los enemigos de Cristo y de su Iglesia utilizaban a los obreros y no precisamente para mejorar su situación:

"Por una multitud de razones, que fuera larga tarea explicar, la clase obrera es hoy objetivo, en que tienen puesta la mira los enemigos de Cristo y de su Iglesia, quienes utilizan las desdichas de los infelices miembros de esa clase y sus aspiraciones, explotan su ignorancia y sus apetitos, no para inclinarlos a buscar el mejoramiento de su suerte dentro de las esferas de lo justo, de lo razonable y de lo lícito, sino sublevándolos contra personas, cosas e instituciones, y para ello los engañan, atribuyendo la culpa de sus infortunios a quien jamás fue su causa, sino antes los deplora vivamente, y anhela su término. El obrero de la hora presente, que sufre, como todos sufrimos y él más que otros, vese asediado de tentaciones".

Esas tentaciones proliferaban en el taller, donde escuchaba las injusticias del capitalista; en el hogar, cuando faltaba lo necesario para la vida; en sus lugares de recreo u ocio, donde la prensa difundía el odio de clases. Y contra esas tentaciones, era lo peor que no había quien les ilustrase, le faltaban guías y maestros que le hagan ver la falsedad de los argumentos que escuchaba por doquier."Por eso -decía el beato Spínola- es desgraciado el obrero, y no puede menos de excitar la conmiseración y el interés del Obispo, que lo ama como un padre a sus hijos". Tras insistir cómo la cuestión obrera afectaba al pobre y al rico, al grande y al pequeño, en definitiva, a la sociedad en común como venían a demostrar las huelgas que expresaban el malestar general, aludía a la preocupación episcopal y a la necesidad de crear estos centros de integración:

"Por estas razones y otras más la suerte de los obreros no puede sernos indiferente, y veríamos con indecible complacencia a los buenos católicos, no escasos por cierto en número entre nosotros, trabajar con ardor en esta empresa, y crear círculos y centros en una u otra forma, donde el obrero

13 MSyM, Circular n 575, Málaga, 15 de abril de 1893. En BOOM, 1893, p. 421. 
hallara lo que ha menester, defensa contra la seducciones y asechanzas de todo linaje, a que se le somete o que se le preparan.

Si el establecimiento de esos círculos, de esos centros es difícil en los pueblos de escaso vecindario, que viven de la agricultura, no lo es en ciudades populosas, de las que hay no pocas en este Arzobispado. Jerez, Utrera, Huelva, Osuna, Écija ¿Por qué no habrán de tener corporaciones católicoobreras?".

\section{Y concluía el beato Spínola sobre su necesidad:}

"Las corporaciones obreras, aunque por su índole sean laicas, siendo católicas no pueden menos de tener en mucha consideración al Clero, e invocar la luz, el consejo, la dirección del Sacerdote, llamado a promover su formación, y a intervenir, ya que no en otra manera con la ciencia y el estímulo de la palabra a su buena marcha.

Por eso nos atrevemos a dirigirnos hoy a nuestros colaboradores en el sagrado ministerio, y a recomendarles y rogarles que no miren con desdén o con pavor, permaneciendo quietos por uno u otro motivo, la causa de los obreros, sino que estudien los medios de reunirlos a fin de que constituyan círculos, centros o asociaciones, con uno $\mathrm{u}$ otro nombre, en las que hallen honesto solaz, a la vez que alimento saludable para su inteligencia y para su corazón, respirando aire sano, en lugar del putrefacto y corrompido del taller" ${ }^{\prime 14}$

Sus planteamientos tenían entonces eco en el boletín diocesano, que se convirtió desde entonces en medio propagandístico de esta compleja obra de social de reencuentro entre clases antagónicas. Ahí daba cuenta de ello poco después en letras que, sin llevar firma, no hay duda que si no eran suyas al menos estaban claramente inspiradas en su pensamiento. Frente a esta realidad, los católicos de entonces, en especial a quienes correspondía la máxima responsabilidad en la empresa, los patronos, solían mirar hacia otro lado:

"Y ¿qué diremos de nuestras corporaciones obreras? No sabemos la causa; pero el hecho es que no se propagan, y que donde se crean arrastran una existencia enfermiza, pudiendo literalmente afirmarse que viven muriendo. Hemos dicho que ignoramos la causa de este doloroso fenómeno, y hemos dicho mal, la conocemos. Es que no hay abnegación entre los católicos, llamados por su posición a dirigir y guiar la clase obrera, a quienes rehúsan sacrificar tiempo, solaz y reposo, prefiriendo las dulzuras del hogar, el recreo de los paseos, de los espectáculos y de las diversiones, y el

14 MSyM, Circular núm. 28, Sevilla, 30 de julio de 1896. En Boletín Oficial del Arzobispado de Sevilla [en adelante BOAS] 1996-2, pp. 47-51. 
provecho del negocio a la poco entretenida tarea de pasar el rato entre los hijos del trabajo, demostrándoles interés y afecto. Es en fin, lo diremos que no se ha conseguido todavía perfeccionar la organización de los Círculos de Obreros y de las demás corporaciones destinadas al bien de estos, y bautizadas con uno u otro nombre" ${ }^{\prime 15}$

En otros textos correspondientes a las mismas fechas se insistía en una responsabilidad compartida por todos los sectores e, incluso, se cuestionaba la idoneidad de este tipo de centros sin proponer otros alternativos:

"Hay quien supone que el obrero ha perdido el sentido moral y cristiano, $\mathrm{y}$, que a eso se debe que oiga con repugnancia o a lo menos con disgusto todo lo que se refiere a la Religión. No por otra razón, dicen, se le llama, y no responde; lo buscamos y nos huye, y si por ventura no osando resistir a nuestros ruegos, acude a la cita, muy luego se cansa, y hastiado se retira y nos deja.

Otros, que no tienen tan triste concepto del obrero español, se fijan para explicar el fenómeno en nuestro carácter nacional, y arrojan pestes contra la incuria de los que en España viven del trabajo, echándoles en rostro que si no por malicia, por indiferencia y apatía, desaprovechan un trascendental e importante beneficio, con que se les brinda.

Algunos culpan por último de lo que acaece a nuestros hábitos, y aún a la escasa cultura de nuestros obreros, más amantes de la taberna, en que al son de las copas se bebe y se canta, que de los Círculos donde se lee, se escribe, se oyen lecciones de doctrina cristiana, y se habla de asuntos serios y graves".

De todo ello podía haber en las dificultades para su difusión y al menos inicial fracaso de los círculos. Se decía entonces, a la llegada del beato Marcelo Spínola a la sede hispalense como arzobispo en 1896, que no se había atinado en su organización, funcionando más bien como escuelas en las que se procuraba enseñar al obrero y resistiéndose este en acudir. Por ello se insistía en que había de ser atendida la dignidad del obrero en el círculo e insistir en cómo acudiendo no perdía su libertad. ${ }^{16}$

A pesar de las enormes dificultades algo se allanó el terreno en estos momentos. En 1892 se había fundado un centro en Dos Hermanas y otro en Jerez de la Frontera, entonces de la archidiócesis. Sabemos

\footnotetext{
15 Pasado y porvenir, en BOAS, 1897-1, pp. 58-63, (la cita en p. 62).

16 Algo sobre los círculos de obreros, en BOAS, 1897,-2, pp. 251-261.
} 
que en 1896 se había fundado en Carmona un Centro Católico instructivo para los obreros. El 12 de febrero de 1898 quedó inaugurado el Círculo Católico de Obreros San Francisco Javier, situado en la sevillana calle San Benito de Calatrava, vinculado a la obra salesiana; el propio Arzobispo acudió a su inauguración en la que intervinieron el Superior del Colegio de la Trinidad, P. Pedro Ricaldone, y el beato Marcelo Spínola quien se refirió a la obra de Don Bosco y reclamó la caridad de los sevillanos en auxilio de la casa "destinada al parecer a prestar servicios de no menos valía que los debidos a la Santísima Trinidad"17. En 1899 las congregaciones marianas de los jesuitas estaban poniendo en pie otro centro de esta naturaleza.

En 1901 se puso en marcha un círculo en Alcalá de Guadaira en el que había una sociedad de socorros mutuos. Ese mismo año se refundaba el círculo de obreros de Jerez de la Frontera de antaño, que llevaba anexo unas escuelas católicas; del hecho se daba noticia en el boletín diocesano con unas letras que, si bien no tenía firma, sin duda recogía el espíritu del preclaro pastor de la archidiócesis sobre los círculos en general y de este en particular gestionado por jóvenes:

"No es necesario encarecer la importancia, que hoy tienen todas las instituciones relacionadas con los Obreros, pues nadie hay que pueda desconocerla, aunque desgraciadamente dichas instituciones no han progresado ni han llegado a multiplicarse en nuestra patria, quizá por incuria o indolencia de los llamados a fomentarlas.

Por misericordia de Dios algunos jóvenes de Jerez, que conservan viva la fe en sus almas, estimulados por un antiguo compañero suyo, ejemplar y celoso Sacerdote, que renunciando a halagadoras esperanzas, se ha vestido la sotana de los ministros de Cristo, han tomado a su cargo la empresa a una obra, que parecía próxima a morir, y el Círculo de Obreros y las escuelas católicas, a él unidas, toman incremento extraordinario con no leve provecho de la clase obrera, tan necesitada de que se le hable el lenguaje de la verdad, en vez de alucinarla con utópicas teorías, que nunca se realizarán, y que anunciadas con lujo de declamatorias imprecaciones, producen y desde luego pavorosas catástrofes.

Sigan su tarea sin cansarse los generosos jóvenes a quienes aludimos, y estén seguros de que Dios les ayudará". ${ }^{18}$

Sección de Noticias, en BOAS, 1898-1, pp. 141-142.

18 El círculo de obreros de Jerez de la Frontera, en BOAS, 1901-1, pp. 308-9. 
Sabemos que en 1903 se habían fundado círculos en Écija, Morón, Montellano, Lebrija y Puebla de Cazalla; en este último se pretendía fomentar la instrucción religiosa, crear una mutualidad, proporcionar trabajo a los parados, gestionar la construcción de viviendas"higiénicas y baratas para la clase obrera", crear un economato y una caja de ahorros, etc. El año siguiente además de funcionar los anteriores, se instaló el de Mairena del Alcor (cooperativa agrícola) y el de Gerena. Ese mismo año comenzaba a funcionar el Centro Católico de Huelva y el de Sevilla; instalado este último en la calle Rivero, donde se dieron interesantes conferencias por los católicos sociales más caracterizados del momento, más adelante se instalaron centro patronales obreros, cooperativas de consumo, de viviendas y hasta un secretariado social para auxiliar legalmente a los obreros. Fueron resultados exiguos todavía, pero sirvieron de base para el desarrollo sin duda extraordinario que tuvieron estas instituciones y otras más novedosas a la muerte del beato Marcelo Spínola, ya propiamente sindicatos católicos agrarios, en un número que se aproxima al centenar y medio en casi un centenar de municipios de la jurisdicción diocesana. ${ }^{19}$

Dentro de la labor en este terreno no debemos olvidar la propaganda que se hacía en los boletines diocesanos de Málaga, sin duda con el beneplácito del prelado, de las obras del P. Enrique de Ossó (El catecismo de los obreros y ricos) y sobre todo del P.Vicente, de entre ellas una de las más famosas como era Socialismo y anarquismo ${ }^{20}$. Una acción que continuaría en Sevilla con respecto a la personalidad del P.Vicent, cuando tras referirse al contenido de sus folletos en el que planteaba el desequilibrio de las clases sociales, aludía también a su gran obra de agremiación de los centros católicos y concluía diciendo que"los trabajos del P.Vicent demuestran una gran fe, no solo en la causa de Dios, que es la que en último término busca, sino en los medios que propone" ${ }^{21}$

No sólo daba cabida de los católico-sociales -como se conocían en la época- más reconocidos del país sino también de aquellos que emergían en su propia diócesis. Cuando el abogado y político

19 Unos apuntes sobre estas incipientes obras pueden verse en José-Leonardo RUIZ SÁNCHEZ, Política e Iglesia durante la Restauración... También en"Fuentes para el estudio del catolicismo social...", donde se da cumplida cuenta del desarrollo de toda esta obra católico social.

20 Ambas noticias en BOOM: 1891, p. 236; y 1893, p. 440, respectivamente.

21 Un importante folleto, en BOAS, 1905-1, pp. 205-6. 
sevillano José Borés Lledo publicó en 1903 un extenso trabajo sobre el asunto, titulado Algunos aspectos de la cuestión social, el boletín diocesano se hizo amplio eco de él. Desde luego que reunía todos los requisitos precisos y por eso se traía a sus páginas: “El criterio a que la obra se ajusta es el netamente católico" y la conclusión de los distintos aspectos analizados en profundidad no eran otra que "los grandes ideales católicos son los que pueden restablecer la paz en la sociedad". ${ }^{22}$

\section{EN PREVENCIÓN DEL MAL Y PALIANDO SUS CONSECUENCIAS}

No quedaría completa la actitud del Beato Marcelo Spínola sobre el mundo del obrero si dejásemos de citar también las distintas medidas preventivas que empleó a lo largo de los años para evitar o al menos paliar algunos de sus males. Algunas fueron iniciativas propias (sus propias letras, valdrían como ejemplo), pero también se valió de instituciones $\mathrm{u}$ organismos a los que promocionó por considerarlos en extremo útiles. A varias de estas obras preventivas nos referimos a continuación.

El beato Spínola siempre tuvo en gran estima la labor que desarrollaban los discípulos de D. Bosco a lo que sumaba su particular devoción a san Francisco de Sales. Siendo obispo auxiliar del cardenal Lluch tuvo ocasión de conocerlos cuando, en 1881, instalaron en Utrera su primera casa en España. De su admiración por el fundador de los salesianos y su obra da cuenta el que fuese el autor de la primera biografía de Don Bosco, escrita aún en vida, en la que refería las virtudes del fundador y su labor contra los males de la época. Siendo obispo de Málaga hizo denodados esfuerzos hasta que consiguió su instalación en la sede en 1895 para que acogieran "a los niños desamparados que tanto abundan en nuestro pueblo, y que faltos de toda educación social, se preparan a ser el oprobio y el escándalo de la sociedad civil y cristiana en el porvenir". Más claro dejó sus intenciones con respecto al obrero cuando en marzo de 1896, nada más llegado a la de Sevilla, hizo la primera visita a los salesianos instalados en La Trinidad, entonces un barrio marginal, obsequiándoles los

22 Algunos aspectos de la cuestión social, en BOAS, 1903-1, pp. 263-264. 
niños acogidos con una fiesta. Así recogía la prensa del momento la trascendencia de la visita:

"La educación completa del obrero cristiano, la enseñanza religiosa y técnica de las clases más pobres y desvalidas, que es el fin primordial del Oratorio, reviste en los tiempos socialistas que corremos una importancia tan excepcional, que nadie ha podido ponerla en duda; antes al contrario, en todas partes se ha reconocido que más ha hecho y hará D. Bosco para resolver el llamado 'pavoroso problema social', que todos los pretendidos sabios y reclamadores que no se han inspirado en el espíritu vivificador de la Iglesia católica.

En el corto tiempo que llevan en Sevilla los salesianos, ya se conocen en el barrio de la Trinidad, donde se hallan establecidos, su beneficiosa influencia, y no tardará en conocerse en todo el pueblo. Más de mil adolescentes pobres acuden a sus escuelas y talleres, y otros cien internos reciben además alimento y cama por milagro de la caridad.Y con ser este el único tesoro de que disponen los hijos de D. Bosco, han podido desarrollar su obra, que posee ya numerosos talleres y una imprenta admirablemente montada, en donde trabajan con afán los pequeñuelos para adquirir un oficio. En menos de un año también han organizado los buenos religiosos una banda de música, poderoso medio de disciplina y recreo" ${ }^{23}$

No había mejor medio para evitar el problema obrero que la enseñanza de un oficio a los más pequeños con el que pudiesen ganarse la vida; el mundo cristiano estaba planteando la formación profesional, de la que los salesianos fueron unos pioneros, cuando ésta ni existía ni era objetivo de la educación pública promovida por el Estado. Era -como decía el comentarista- una "caritativa obra", pero con la que podía remediarse el problema social al sacar de la marginalidad a la que estaba abocada la juventud sin ningún futuro profesional. No solo a la juventud: con los salesianos contó, como hemos referido un poco más arriba, para instalar dos años más tarde un círculo católico en la misma sede.

La admiración del beato Spínola hacia Don Bosco y su obra fue una constante a lo largo de los años. Los puso como ejemplo de cristianos que aborrecen la injusticia y son amigos íntimos de los obreros a quienes Jesucristo los amaba"con el amor del más fiel de los amigos". Y añadía:

23 La noticia de la prensa fue reproducida en el boletín diocesano. Sección de noticias, en BOAS, 1896-1, pp. 217-220. 
"[...] el amor, decimos, que D. Bosco tuvo al obrero está patente en su obra de los Talleres Salesianos.

Allí no se especula; no se utilizan los brazos del adolescentes y del joven a fin de hacerlos producir y así crear una respetable riqueza para el establecimiento que los ampara; solo se procura una cosa, formar obreros cristianos, católicos, o sea, preservar al individuo de la corrupción y el vicio, que son su ruina, y regenerar la clase obrera, introduciendo en sus venas sangre sana, que le de vida robusta y vigorosa". ${ }^{24}$

Junto a ellos y ante una realidad distinta, pero también educativa, se puso en marcha con carácter diocesano en 1902 el"Apostolado de Señoras para el mejoramiento moral y social de la clase obrera". Su fin era llevar la instrucción a los obreros y obreras. Sólo en Sevilla tenían acogidas a más de tres mil y en el total de las 26 poblaciones en las que estaban instaladas educaban a 24.705 personas de ambos sexos. "Las señoras católicas -decía el boletín diocesano- hacen indudablemente en favor de esta clase, tan necesitada hoy del pan de la verdad, más que hacen los hombres, los cuales se cuidan muy poco de esos hijos del pueblo, a quienes explotadores que con engañosas promesas los halagan, llevan a la ruina". ${ }^{25}$

Un problema que afectaba entonces a las operarias con hijos menores sobre todo, era la seguridad de los mismos cuando ellas estaban trabajando o la atención durante una larga jornada laboral, que no podían abandonar ni siquiera para darles de comer. A comienzos de 1901 quedó constituida en la Capilla del Palacio Arzobispal el Patronato de la Niñez.

"Es un problema, al que no se había dado solución entre nosotros, el de facilitar a las operarias, que trabajan en la fábrica de tabacos o en otros establecimientos industriales en que pasan la mayor parte del día, medio de que dejasen tranquilamente a sus hijos en la seguridad de que se hallaban al abrigo de todo peligro.

El asunto era serio. Las operarias, a que nos referimos, no podían renunciar a la fábrica o al taller, porque sin su jornal morirían ellas y los suyos, y los niños, abandonados a sí propios, y vagando por las calles corrían riesgos de muchas clases, no siendo raros los atropellamientos por los carruajes o los tranvías y mil otros accidentes, y sobre todo haciéndose casi imposible que,

24 MSyM, A nuestros amados diocesanos los obreros de Sevilla, Sevilla, 25 de octubre de 1901. En BOAS, 1901-2, pp. 277-278.

25 Apostolado de Señoras para el mejoramiento moral y social de la clase trabajadora, en BOAS, 1902-2, pp. 231-232. 
juntándose con mancebos ya picardeados y acaso encegados en el vicio, y viendo y oyendo tanto malo, no se corrompiesen". ${ }^{26}$

A tal fin, un grupo de señoras caritativas habían puesto en marcha una obra que conllevaba el que los pequeños no saliesen de las escuelas al mediodía, entre las clases de la mañana y la tarde, mediante el establecimiento de esta permanencia escolar que garantizaba la tranquilidad de las trabajadoras en unos tiempos en los que (se hace preciso exponer) no existían las guarderías escolares.

En esa prevención del mal también debemos situar sus letras a modo de pastorales, instrucciones, circulares y noticias publicadas en el boletín diocesano, solo puntualmente referidas aquí. Siempre lo hizo mostrando una comprensión paternal hacia los más necesitados, incluso en difíciles circunstancias. Sabía de la animadversión que podía suscitar el que un obispo se dirigiese a los obreros pues, como él mismo apuntaba,"serían [sus letras] acogidas con mofa, prevenidos como se hallan los ánimos de los hombres del pueblo contra los que vestimos sotana, y muy particularmente contra los que empuñamos el báculo pastoral". No obstante, no permaneció al margen cuando lo creyó necesario como hemos tenido ocasión de observar. Su intervención en 1901 tuvo un matiz distinto: a comienzos de ese año reverdeció el anticlericalismo en todo el país, también en la ciudad de Sevilla (estreno de Electra de Galdós; el anticlericalismo como arma política durante la campaña electoral) pero lo hizo de una manera radical aquí durante el mes de octubre cuando se cometieron distintos atentados contra personas y cosas sagradas. Unas fechas antes se había denunciado el interés de los oradores de las asambleas obreras por descatolizar, por hacer ateo al obrero, y echar las culpas de su maltrecha situación a los capitalistas apoyados"por la Iglesia y sus representantes". Tras los sucesos tomó su pluma para denunciar el engaño al que era sometido el trabajador por ideologías que sólo terminarían provocando su ruina al prometerle cosas imposibles de conseguir; su grandeza quedaba rubricada cuando, a pesar de lo ocurrido, decían que le movía a hablar "la compasión paternal que nos inspira el pobre obrero". ${ }^{27}$

\footnotetext{
26 Una obra de caridad más en Sevilla, en BOAS, 1901-1, pp. 173-4.

27 MSyM, A nuestros amados diocesanos los obreros de Sevilla, Sevilla, 25 de octubre de 1901. En BOAS, 1901-2, pp. 265-279.
} 


\section{SIEMPRE CON EL PENSAMIENTO PUESTO EN LO MÁS ALTO}

Como vemos, a la hora de arbitrar soluciones para afrontar la cuestión social no le faltó el concurso humano. En un hombre de profunda espiritualidad tampoco podía quedar marginada la búsqueda del concurso divino en su resolución, como así nos consta. Dentro de su obligada ilustración cristiana como pastor de su grey, en no pocas ocasiones denunció las ideologías emergentes, que amenazaban la misma sociedad. En referencia expresa al anarquismo ("un enemigo, con el que no contábamos, ha aparecido súbito, y con furia satánica dispónese a acabar con todo cuanto hay respetable en el mundo, no reparando en medios") que buscaba captar en gran medida la atención de los obreros en su desesperación y que había"negado la autoridad de la Iglesia, la divinidad de Cristo, el orden sobrenatural, el cielo y el infierno" además de proclamar que"no hay más vida que la presente, y que al otro lado del sepulcro no se halla sino la nada"; decía el beato Marcelo Spínola que para "ahuyentar este monstruo" no bastaba el rigor de la leyes, como acreditaba la experiencia, sino que era necesario algo más elevado:

"[...] necesítase llegar allí donde el legislador humano no puede penetrar con sus medidas autoritarias; a los corazones, a las almas, y en ellas infundir el espíritu de caridad, que es benigno, dulce, sufrido, indulgente, generoso, expansivo; que es la antítesis del egoísmo y el polo opuesto de la dureza y la crueldad; que es no el amor arrollando cuanto le sale al encuentro, sino el amor de los demás sacrificándose por su bien.

Este espíritu es el que respiramos cuando nos acercamos a la Santísima Virgen" ${ }^{28}$

La referencia a la Virgen como mediadora para conjurar el mal en el que podían caer los obreros quedaba expresada en la alocución que hizo con ocasión de recordar y recomendar a los malacitanos la práctica del piadoso ejercicio del Mes de las Flores o Mes de María.

Por poco que se conozca la espiritualidad del beato Marcelo Spínola sí que se sabe que su devoción preferida, junto a la anterior, fue al Sagrado Corazón de Jesús como queda acreditado nada más ver su escudo pontificio. Poco después del texto anterior escribió

28 MSyM, Circular Número 543, Málaga, 20 de marzo de 1892. En BOOM, 1892, pp. 77-80. 
otro en el que manifestaba la necesidad de que los católicos fuesen devotos de Él, de su amor, que serviría para acabar las injusticias cometidas contra el obrero que no eran sino fruto de la codicia del capitalista y que serviría para implantar la necesaria fraternidad humana:

"Sí, indudablemente la devoción al Corazón de Jesús, que reforma al obrero, reformaría al jefe del taller o la fábrica, al capitalista, y restauraría las relaciones mutuas de los unos y los otros, resolviendo la pavorosa cuestión, que preocupa hoy tanto a los hombres de Estado". ${ }^{29}$

Un año más tarde, cuando en las manifestaciones obreras de 1893 promovidas por el internacionalismo obrero al tiempo que demandaban derechos para sus simpatizantes exteriorizaban su odio a la religión, en clara sintonía con el Papa reclamaba Spínola la necesidad de impulsar la restauración cristiana en la sociedad ("porque donde no hay Dios, no hay derecho, no hay justicia, no hay ley moral, no hay subordinación, no hay orden, toda vez que esas grandes ideas son derivaciones de la idea fundamental de Dios, y solo reinarían por consiguiente las pasiones con sus brutales exigencias y con espantosos desenfrenos") y proponía -entre otras medidas para su consecución- la fundación de los círculos católicos de obreros que evitarían la corrupción de las almas de sus asociados haciéndoles sentir el atractivo de lo espiritual y divino, apuntaba también quien podía ser mediadora en todo ello:

“Mas es cierto que nada tanto a él conduce como la devoción a la Santísima Virgen, de quien puede afirmarse que es la precursora de Cristo en los corazones, en los hogares y en los pueblos, preparándole el camino para que verifique su entrada en ellos". ${ }^{30}$

\section{UN REFERENTE, EN DEFINITIVA, PARA LOS OBREROS}

El beato Marcelo Spínola y Maestre se terminó convirtiendo con el paso del tiempo por su pensamiento y por su obra en un referente para los obreros. En 1899 un grupo de dependientes del comercio sevillano se dirigieron a él para que -decía el propio Spínola- en la

\footnotetext{
29 MSyM, A nuestros amados diocesanos, Málaga, 20 de mayo de 1892. En BOOM, 1892, p. 110.

30 MSyM, Circular n 575, Málaga, 15 de abril de 1893. En BOOM, 1893, pp. 420-421.
} 
negociación con sus patronos, les ayudase a"conseguir el fin cristiano y justísimo [...] de que se cerrasen todas las tiendas el día festivo, y se otorgasen a los empleados en ellas el descanso, que reclaman a una la razón y la religión". Ya en 1891, cuando era senador en representación de la Provincia Eclesiástica de Granada, había defendido desde la tribuna de el Senado esta misma medida frente a políticos liberales que la rechazaban por entender en su opinión que era la consecución de un privilegio eclesiástico más ${ }^{31}$. El asunto le interesó, pero esperó paciente al resultado de las negociaciones, finalmente favorables a lo planteado por los operarios del comercio. Entonces sí se expresó públicamente en un sentido en el que reunía la naturaleza religiosa por la santificación del día con la más mundana y también humana de recuperar energías y necesidad del recreo:

"Creemos por lo mismo llegada la hora de que Nos hablemos siquiera sean
pocas palabras, porque pocas palabras bastarán a nuestro propósito.
Y desde luego declararemos que el reposo del día festivo es exigencia de
la Religión, la cual reclama con sobrado derecho que, ya que tantos días
dedicamos a procurar los intereses mundanales, consagremos a Dios algu-
no que, otro en el año o en el mes. Es necesidad además de la naturaleza,
pues el organismo humano ha menester de tiempo en tiempo abandonar
el cotidiano trabajo, que lo desgasta y en entregarse a honestas expansio-
nes, a recreaciones lícitas, que desahoguen el pecho oprimido y restauren
las abatidas fuerzas. Es medio por último eficacísimo de levantar el espíritu
del tráfago de los negocios o las labores, de los enojosos cálculos del tanto
por ciento...". ${ }^{32}$

Esa misma sensibilidad hacia todo lo relacionado con el mundo obrero queda corroborada cuando se aprobó en 1900 una de las incipientes leyes sociales españolas, referida al trabajo de los niños y de las mujeres. La prohibición del trabajo de los menores de 10 años y no más de 6 horas los comprendidos entre los 10 y los 14 años; prohibición del trabajo nocturno de todos ellos; prohibición del trabajo a las menores de edad en talleres donde se confeccionen escritos, grabados, estampas, etc., que pudieran herir su moralidad; prohibición del trabajo en domingos y festivos; concesión de dos horas diarias,

31 Sus intervenciones al respecto, los días 8 y 9 de junio de 1891, pueden seguirse en el extracto oficial que figura en el Diario de Sesiones del Senado correspondientes a esos días, fascículos 63 y 64.

32 MSyM, El descanso dominical. En BOAS, 1899-2, pp. 20-22. 
no computables entre las de trabajo, a los menores de 14 años para que adquiriesen instrucción primaria y religiosa figuraba, entre otras propuestas, en el articulado de la ley. El beato Spínola, no sólo reprodujo íntegramente en el boletín diocesano toda la ley sino que indicó expresamente que podía ser su conocimiento muy útil a los párrocos, quienes deberían velar por su cumplimiento. ${ }^{33}$

En esa brecha continuó hasta los últimos momentos. En 1904 san Pío X promulgó el motu proprio La acción popular cristiana, en la que se recogía su propuesta sobre la acción católica de los seglares. Sin duda el beato Spínola se mostraría contento y por supuesto en consonancia con las letras pontificias que establecían cómo"para resolver las diferencias entre ricos y los proletarios es preciso distinguir la justicia de la caridad. No se tiene derecho a reivindicaciones sino cuando se ha lesionado la justicia". También cuando se establecía como obligación del obrero el "prestar entera y fielmente el trabajo que libremente y según equidad fue pactado; no hacer daño a la hacienda ni ofensa a la persona de los patronos; en la misma defensa de los derechos propios abstenerse de actos violentos y no transformarla jamás en motines". Y en el caso de los capitalistas "pagar lo justo a los operarios; no perjudicar sus justos ahorros ni con violencia, ni con frialdad, ni con usuras manifiestas o encubiertas; darles su libertad para cumplir con los deberes religiosos; no exponerles a seducciones corruptoras y a peligros de escándalos; no apartarlos del amor de la familia y del ahorro; no imponerles trabajos desproporcionados a sus fuerzas, o mal avenidos con la edad o con el sexo". Y cómo no iba a estar de acuerdo con el Papa santo cuando manifestaba que "a la resolución del problema obrero pueden contribuir en gran parte los capitalistas y mismos obreros con instituciones encaminadas a proporcionar oportunos socorros a los necesitados, y a aproximar y unir las dos clases lo más íntimamente posible". Las palabras del Santo Padre, que instaba a que esas reglas debían ser tratadas en los círculos de obreros o centros de naturaleza y forma similar, fueron llevadas al boletín diocesano de Sevilla. ${ }^{34}$

33 Ley interesante, en BOAS, 1900-2, pp. 222-227. Aunque el texto no lleve la firma del Beato Marcelo Spínola, deducimos su autoría o al menos su inspiración por cuanto en la nota introductoria se daban instrucciones a los párrocos, algo que sólo correspondía jerárquicamente él o a algún colaborador instado por él.

34 La Acción Popular Cristiana. Pio, Papa X. Motu proprio, Roma, 18 de diciembre de 1903. En BOAS, 1904-1, pp. 4-13. 


\section{$* * *$}

Más allá de los casos concretos y hechos más relevantes que se han expuesto en las líneas anteriores, el beato Marcelo Spínola y Maestre mostró siempre una particular sensibilidad en todo lo relacionado con la cuestión social del momento. Intervino en ese complejo mecanismo que regulaba las relaciones entre capital y trabajo aportando su criterio, que estaban en consonancia con el del magisterio de la Iglesia, y poniendo en marcha en su jurisdicción los mecanismos que entonces se prodigaban. En este difícil equilibrio siempre se decantó por la parte más débil y necesitada, los obreros, para los que procuró remediar su situación y que se impusiese la justicia social; no por ello denunció los excesos que también cometían, al igual que los dueños del capital, pero en este caso siempre responsabilizó de los mismos a quienes con sus prédicas les llenaban sus cabezas con planteamientos fuera de lo razonable y, por tanto, en su opinión irrealizables. 